\title{
El uso de trillos durante la Edad del Cobre en la Meseta española. Análisis traceológico de una colección de denticulados de sílex procedentes del 'recinto de fosos' de El Casetón de la Era (Villalba de los Alcores, Valladolid)
}

\author{
Evidence of the use of threshing-boards in the spanish Meseta during the Copper Age. \\ Microwear analysis of flint denticulates from 'the ditched enclosure' of El Casetón \\ de la Era (Villalba de los Alcores, Valladolid)
}

\author{
Juan Francisco Gibaja (*) \\ Manuel Crespo (**) \\ Germán Delibes $(* *)$ \\ Julio Fernández $(* *)$
}

\section{RESUMEN}

La presencia de grandes piezas líticas talladas bifacialmente es una constante en los contextos de la Edad del Cobre en el interior de la Península Ibérica. El brillo apreciable a simple vista en su filo denticulado ha sido atribuido a su uso como hoz. El estudio que ahora presentamos contradice parcialmente esta propuesta, ya que la mayor parte de las piezas halladas en el yacimiento de El Casetón de la Era (Villalba de los Alcores, Valladolid) no eran hoces sino elementos de trillo. Estamos ante las evidencias más antiguas de su uso en la Península Ibérica. Este tipo de piezas tienen cierta semejanza con las encontradas en el Próximo Oriente durante la Edad del Bronce.

\footnotetext{
ABSTRACT

Large bifacial flint tools are frequently found in Copper Age sites from Iberian Península. They usually show a visible gloss on their denticulated working edges, pos-

(*) Investigador contratado por el Ministerio de Ciencia e Innovación, Subprograma Ramón y Cajal. Dpto. de Arqueología y Antropología. Institución Milá y Fontanals - Consejo Superior de Investigaciones Científicas (IMF-CSIC). C/ Egipciàques 15. 08001 Barcelona. Correo e.: jfgibaja@imf.csic.es

(**) Dpto. de Prehistoria, Arqueología, Antropología Social y Ciencias y Técnicas Historiográficas, Facultad de Filosofía y Letras, Universidad de Valladolid. Plaza del Campus $\mathrm{s} / \mathrm{n}$. 47011 Valladolid. Correos e.: crespomanue169@gmail.com; delibes@fyl.uva.es; jferman@fyl.uva.es; kisstinapucela@hotmail.com; joseiherran@terra.es
}

\author{
Cristina Fraile $(* *)$ \\ José Ignacio Herrán $(* *)$ \\ Antoni Palomo (***) \\ José Antonio Rodríguez (****)
}

sibly related to cereal cutting. As a result, these tools have been interpreted as sickle blades. This paper partially contradicts this hypothesis, since most of the pieces recovered at the site of El Casetón de la Era (Villalba de los Alcores, Valladolid) were not used as sickles, but rather they could have been flakes in threshing-boards. Therefore, this is the earliest evidence of the use of threshingboards in Iberia. This type of tool is in some way similar to those found in the Near East during the Bronze Age.

Palabras clave: Mediterráneo occidental; Prehistoria reciente; Arqueología experimental; Tecnología; Trillos; Agricultura; Cereal; Traceología.

Key words: Western Mediterranean; Late Prehistory; Experimental archaeology; Technology; Threshingboards; Agriculture; Cereal; Use-wear analysis.

\section{EL YACIMIENTO DE EL CASETÓN DE LA ERA}

Tal vez por asumir la superioridad del instrumental metálico sobre el de piedra, los prehisto-

(***) Arqueolitic. Carrer Sant Martirià 56. 17820 Banyoles Girona. Correo e.: tpalomo@arqueolitic.com

(****) Dpto. de Ciencias Históricas y Geografía, Área de Prehistoria, Facultad de Humanidades y Educación, Universidad de Burgos. C/ Villadiego s/n. 09001 Burgos. Correo e.: jrmarcos@ubu.es

Recibido: 7-I-2011; aceptado: 16-III-2011. 
riadores apenas han prestado atención hasta ahora al utillaje lítico de las Edades del Cobre y del Bronce. En consecuencia, no existe una tradición de estudios traceológicos sobre dichos materiales. Evidentemente, se trata de una situación a revisar. En primer lugar, la piedra era todavía en aquellas épocas una materia prima esencial y muy común para producir todo tipo de artefactos. Recuérdese la insistencia de L. Siret (1913: 30) en proclamar que Los Millares constituía el 'apogeo' de las industrias líticas de la Prehistoria del Sudeste de la Península Ibérica y, sobre todo, la traceología, cuyo campo de aplicación inicial fueron contextos paleolíticos y neolíticos, se ha revelado como un medio muy solvente de aproximación a la funcionalidad de los útiles de cualquier época y contexto (Clop et al. 2001, 2006; Gibaja et al. 2004; Gibaja et al. 2005).

Con la esperanza, entonces, de reconducir la situación o de invertir tan negativa tendencia presentamos ahora los frutos, muy estimulantes, del estudio de casi tres decenas de denticulados de sílex de un yacimiento de la Edad del Cobre de la Submeseta Norte, El Casetón de la Era en Villalba de los Alcores (Valladolid), como muestra de las interesantes revelaciones que aún cabe esperar de la investigación traceológica sobre instrumentos de la Edad de los Metales.

Casi en el límite de las provincias de Valladolid y Palencia (Fig. 1), El Casetón de la Era se ubica sobre una suave loma, actualmente cultivada de cereal, que se alza un par de metros por encima de la confluencia de los arroyos de la

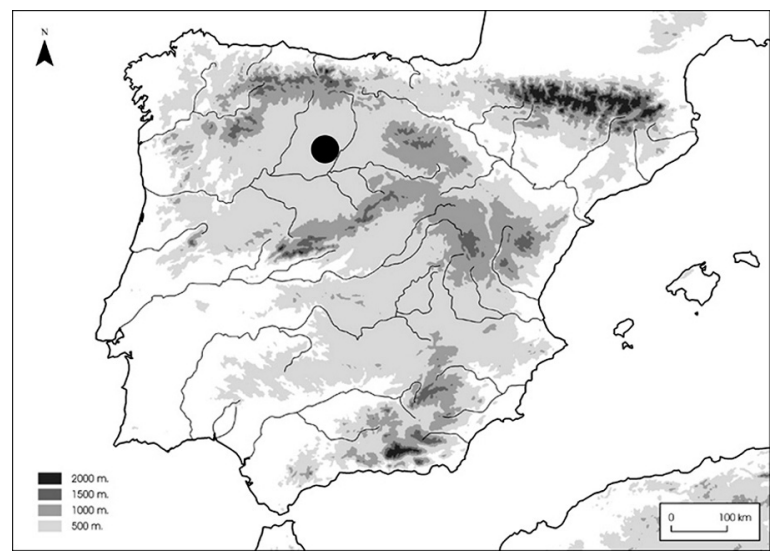

Fig. 1. Localización de El Casetón de la Era (Villalba de los Alcores, Valladolid) en la Península Ibérica.
Moraleja y Mijares, tributarios del río Sequillo. En rigor, se trata de un emplazamiento en llanura, pero su posición ligeramente destacada sobre el terreno circundante situado sobre las cuestas de la vertiente septentrional de los Montes Torozos hace posible divisar desde él una vastísima extensión de la Tierra de Campos palentina.

Entre 2006 y 2010 el yacimiento ha sido objeto de cinco campañas de excavación por parte de arqueólogos de las Universidades de Valladolid y Burgos, las cuales se programaron a raíz del descubrimiento por medio de la fotografía aérea de un 'recinto de fosos' análogo a los conocidos en otras áreas de la Meseta (Díaz del Río 2003). La batería de dataciones (Fig. 2) obtenida en el transcurso de tales trabajos nos permite hoy afirmar que la primera y más importante ocupación del lugar, con los fosos como principales protagonistas, se sitúa en el segundo cuarto del III milenio a.C., en estricta correspondencia, por tanto, con el horizonte calcolítico precampaniforme que en este sector de la Meseta recibe el nombre de 'Los Cercados-Las Pozas' (Delibes y Herrán 2007: 137-180)(1). Luego, cuando los fosos estaban ya del todo colmatados y en vísperas del inicio del horizonte campaniforme, el sitio se abandonó por completo y solo avanzada la Edad del Bronce El Casetón volvió a ser frecuentado en varios momentos del desarrollo de Cogotas I, lo que tuvo como principal consecuencia la aparición de un típico 'campo de hoyos'.

A la ocupación calcolítica, que es la que ahora nos interesa, corresponden tres grandes fosos de planta aproximadamente circular que adoptan



Fig. 2. Dataciones calibradas de C14 de El Casetón de la Era (Villalba de los Alcores, Valladolid). Datos atmosféricos de Reimer et al. (2004), Qx Cal v3. T 0 Bronk Ramsey (2005).

(1) García Barrios, A. S. 2008: Los inicios de la Edad del Cobre en el valle medio del Duero: una aproximación a los modos de vida en el centro de la Meseta en los albores de la metalurgia. Tesis Doctoral. Universidad de Valladolid, inédita. 
una disposición concéntrica (Fig. 3). El exterior, ligeramente ovalado y con un diámetro cercano a los $150 \mathrm{~m}$, delimita un amplio espacio de 1,8 ha que, a juzgar por los hallazgos superficiales, no contiene la totalidad del yacimiento. Las tres 'trincheras' cuentan con puertas, algunas claramente alineadas, sin que en la única que ha sido excavada se adviertan, más allá de la interrupción de la línea de foso, elementos monumentalizadores o de refuerzo. Según suele ser común en esta clase de estructuras (Márquez 2001: 210), los fosos de El Casetón son irregulares, con notables desigualdades a lo largo del trazado, aunque podría hablarse de unas dimensiones medias de $2 \mathrm{~m}$ de profundidad y de $3 \mathrm{~m}$ de anchura, así como de una sección variable - en ' $U$ ' o 'V'- en los casi

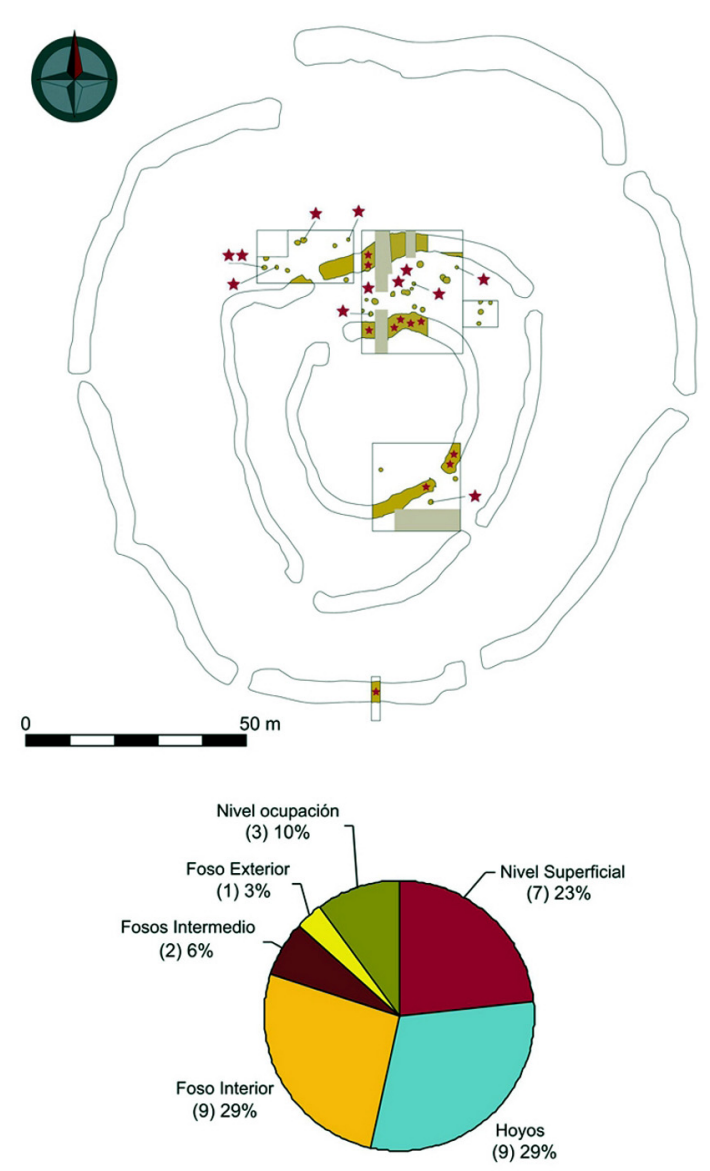

Fig. 3. Grandes fosos de planta circular en El Casetón de la Era (Villalba de los Alcores, Valladolid). Las estrellas localizan en el plano los 31 dentales de trillo y el gráfico los cuantifica por contextos estratigráficos.

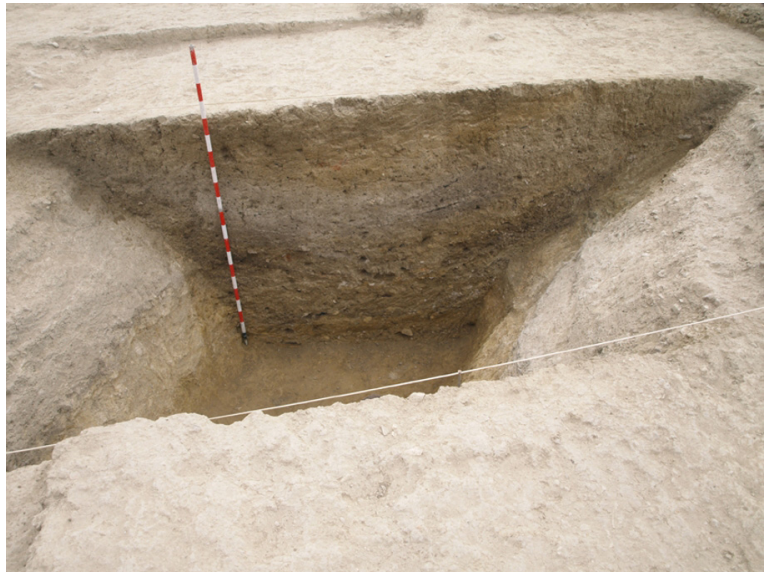

Fig. 4. Vista de la sección del Foso 1 de El Casetón de la Era (Villalba de los Alcores, Valladolid).

$1.000 \mathrm{~m}$ lineales que resultan de sumar el perímetro de los tres recintos (Fig. 4).

Según adelantáramos más arriba, la colmatación de los fosos de El Casetón de la Era tuvo lugar durante la ocupación calcolítica a través de un proceso que no fue ni regular ni homogéneo. Las secciones de los distintos cortes hacen patente la alternancia de lechos de sedimentos finos, ricos en materia orgánica, en despojos de fauna $y$ en restos de cultura material, con otros donde el vertido está compuesto por capas de cierta potencia sin apenas elementos arqueológicos. Tales diferencias, según los estudios sedimentológicos llevados a cabo en 2006(2), responden a dinámicas de relleno diferenciadas, en el primer caso de naturaleza antrópica, y en el segundo protagonizada por diferentes agentes erosivos. Independientemente de la naturaleza de tales procesos, tras la colmatación rápida y absoluta de las estructuras se adivina la misma voluntad sistemática de amortizarlas y de hacerlas desaparecer ya denunciada en otros yacimientos de este mismo tipo (p.e., Márquez y Jiménez 2008: 164-165).

Pero si los fosos fueron en algún momento, sin duda, un elemento delimitador y una referencia de primer orden a la hora de vertebrar el espacio, no resulta tan clara la forma en que se utilizó este por cuanto la mayor parte de las estructuras exhumadas en su interior son esos polémicos 'hoyos' de la Prehistoria Reciente de la Meseta a los que, según conviene y sin mayor

(2) Delgado, J. 2007: Informe geológico del yacimiento arqueológico de Matallana (Valladolid). Texto mecanografiado. 
esfuerzo argumental, se tacha lo mismo de silos que de basureros. Novedad destacable en El Casetón de la Era es que tales hoyos se atienen nada excepcionalmente a unos gestos de colmatación pautados, detectándose en su parte superior espesos 'tapones' de barro limpio (entre 25 y $40 \mathrm{~cm}$ ) que se diría sirvieron para sellarlos. Y además, aunque debajo de dichos 'tapones' se registran rellenos en los que dominan el componente orgánico (cenizas y carbones) y los desechos constructivos (pellas de barro de manteado, con improntas de ramas y/o troncos), mezclados entre las cenizas aparecen de manera recurrente tanto instrumentos en perfecto estado de uso (molinos de mano, hachas pulimentadas, herramientas de hueso, vasijas completas, etc.), como valiosas piezas de carne (las ancas de una ternera con los huesos en perfecta conexión anatómica), lo que no deja de ser una invitación para considerar la condición ceremonial del yacimiento.

En las últimas campañas de excavación se han identificado algunas 'zanjas de cimentación de planta circular' que, por comparación con otras conocidas en la zona de Madrid (Díaz del Río 2003: 69-70), podrían responder a auténticos fondos de cabaña (Fig. 2). Pero la excepcionalidad de tales estructuras en los más de $1.000 \mathrm{~m}^{2}$ excavados en El Casetón y la rareza en su interior o en sus inmediaciones del mobiliario exigible a espacios incuestionablemente domésticos (ni un solo hogar, por ejemplo) justifican las dudas que todavía tenemos sobre el carácter exclusivamente habitacional del sitio, por más que la ingente acumulación de detritus en los fosos remita expresamente a la existencia allí mismo o en las inmediaciones de un área de intenso consumo. Entre tales detritus se cuentan por decenas de millares los vestigios de cerámica y de pedernal con huellas de transformación (Fig. 5), los restos de fauna, los barros con improntas de manteado, los molinos... y no falta algún objeto de cobre que, a juzgar por el hallazgo de un crisol que aún conservaba adherido su régulo, es posible se fundiera allí mismo, pese al centenar largo de kilómetros que separa Villalba de los Alcores de los veneros cupríferos más próximos (Delibes et al. 2009a; 2009b).

Entre tantos materiales queremos destacar aquí la recuperación de 26 objetos de sílex negro y marrón lleno de impurezas disponible sin límite a unos cientos de metros de El Casetón. Lejos de constituir un conjunto de época, proceden de diferentes partes del yacimiento y de los contex-

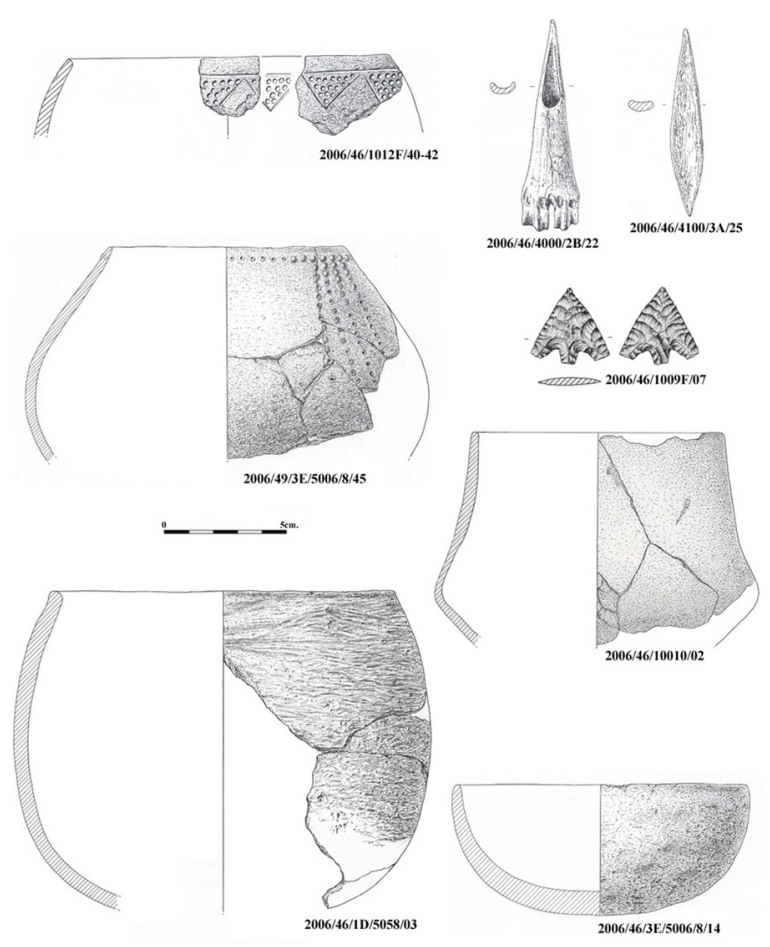

Fig. 5. Restos cerámicos, líticos y óseos documentados en El Casetón de la Era (Villalba de los Alcores, Valladolid). Dibujos de Ángel Rodríguez González y Patricia Arroyo Arroyo.

tos más dispares: fosos, muladares al aire libre, hoyos-basurero y pozos de ofrendas o con 'depósitos estructurados', como denominan ciertos autores a aquellos que contienen cuerpos de perros o de rumiantes domésticos, juegos de molinos, vasos completos o valiosas herramientas en perfecto estado de uso (Márquez 2006)(3).

\section{EL UTILLAJE LÍTICO. CARACTERIZACIÓN MORFOTÉCNICA}

El utillaje analizado está configurado bifacialmente, sobre una lasca espesa y alargada (Fig. 6), con un filo denticulado y cubierto por un fuerte

(3) En la figura 3 se incluyen 31 piezas foliáceas halladas entre 2006 y 2009. De estas 31 no han podido analizarse 5 por estar depositadas en el Museo de Valladolid. Aparecieron en la campaña del año 2006: 2 en el relleno del Foso 2; 1 en el relleno del Foso 1; 1 en el nivel de ocupación y 1 en el hoyo n. $^{\circ} 3$. 


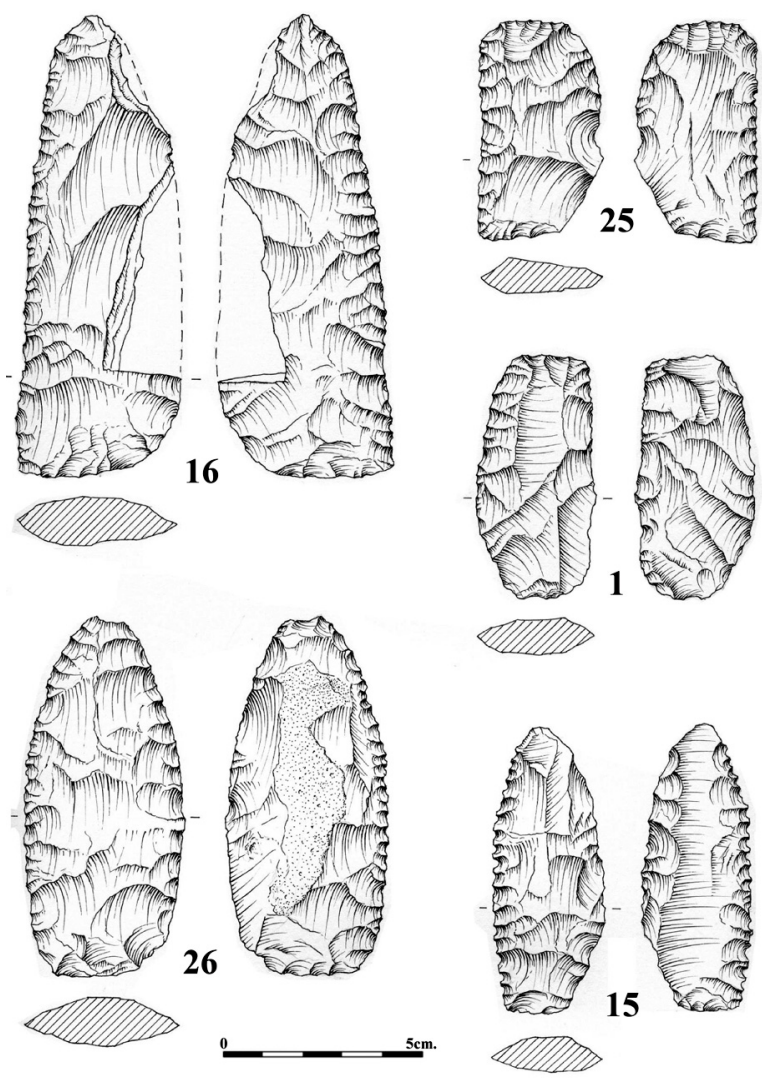

Fig. 6. Algunas de las piezas bifaciales de sílex representativas de El Casetón de la Era (Villalba de los Alcores, Valladolid) que han sido objeto de este estudio. Se especifican los números de inventario (Tab. 1). Dibujos de Ángel Rodríguez González.

lustre que no es distinto del que suele atribuirse a los 'elementos de hoz' en otros yacimientos coetáneos (Benavente 1992). El presente estudio traceológico, como vamos a ver, ha sido decisivo para determinar la verdadera forma de uso de tales piezas.

El utillaje de El Casetón de la Era ha sido elaborado a partir de variedades de sílex, todas locales, como ya se dijo, de cuya explotación en la Prehistoria existen multitud de testimonios en el vasto páramo de Torozos. Sería demasiada distracción enumerarlos, pero parece obligado mencionar siquiera el taller de Los Cercados en Mucientes. Perfectamente coetáneo de nuestro yacimiento y a solo una veintena de kilómetros de él, se ha revelado como un centro especializado en la fabricación de los denticulados que ahora nos ocupan (Delibes et al. 1995). La presencia allí de percuto- res de cuarcita, de percutores/retocadores de asta de ciervo y de compresores de hueso, unida a nódulos, núcleos, lascas y láminas de sílex, a más de algunas piezas fracturadas en los últimos pasos de la fabricación, permite reconstruir la cadena operativa completa por la que se regía la producción de estas piezas bifaciales que hasta ahora se creían elementos de hoz y que en la actualidad todavía pasan por ser uno de los mejores fósilesguía del Calcolítico de esta zona.

El proceso de elaboración de estas piezas foliáceas de El Casetón de la Era sigue, en general, distintas fases:

a. En primer lugar se obtienen grandes lascas espesas y alargadas a partir de la explotación de núcleos tallados mediante percusión directa con percutores duros inorgánicos. Se refleja en los talones lisos o diedros y bastante anchos que se aprecian en unas cuantas piezas, así como en los bulbos marcados y puntos de impacto evidentes.

b. Es probable que algunos de los soportes se calentaran con el fin de disminuir su dureza y facilitar el proceso de configuración bifacial de estas piezas. Aunque tenemos ciertas dudas sobre este hecho, pues el brillo que se aprecia en varias de ellas quizás no es tanto producto del tratamiento térmico como de la propia naturaleza estructural de ciertas variedades de sílex, este sistema técnico no nos parecería extraño ya que ha sido documentado en la Península Ibérica de manera continuada desde el Neolítico antiguo hasta momentos posteriores a la Edad del Bronce (Carvalho 2008; Gibaja 2003). Un ejemplo excepcional lo encontramos en el yacimiento del Caserío de Perales del Río, perteneciente cronológicamente a los horizontes Protocogotas y Cogotas I, con soportes bifaciales tallados tras ser tratados térmicamente (Carrión et al. 2004). Precisamente, los autores del citado trabajo se preguntan si esas piezas se destinaban finalmente a las actividades de siega.

c. Posteriormente, se inicia el proceso de configuración del soporte mediante extracciones planas y cubrientes. El proceso de reducción bifacial del soporte tiene como objetivo generar un filo regular y una sección longitudinal y transversal de tendencia biconvexa. El proceso se inicia priorizando las extracciones anchas y cubrientes de la cara dorsal. Mediante este proceso el filo adquiere una delineación recta que permite configurar la cara ventral posteriormente. La percusión posiblemente se efectuó con un percutor orgánico como los confeccionados en asta. Tenemos docu- 
mentados varios percutores de este tipo en el cercano taller de Los Cercados de Mucientes o en otros contextos calcolíticos del centro peninsular como el Camino de las Yeseras, donde además las piezas bifaciales presentan un lustre en el filo que se considera producto del corte de cereales (Blasco et al. 2007). Las siguientes extracciones adelgazan la cara ventral. La forma final es una pieza cuadrangular o losángica con el extremo distal y proximal recto o eventualmente apuntado. La sección es plano-convexa y el filo activo recto, no convexo como el que va a ser enmangado. Ni siquiera se han eliminado del todo las facetas corticales, cuando su espesor no representaba problema alguno para el futuro enmangamiento. Un grupo de piezas no han llegado a configurarse a través de la reducción bifacial. Debieron fracturarse durante su elaboración ya que se encuentran sin usar.

d. El proceso de reducción bifacial del soporte finalizaba con el adelgazamiento de los extremos distal y proximal mediante extracciones paralelas al eje de la pieza. Esta operación parece estar relacionada con la adecuación de la simetría del útil para facilitar su enmangamiento.

e. Finalmente, utilizando un compresor quizás de metal o asta, se lleva a cabo el cuidadoso denticulado bifacial que será la parte activa del instrumento. Este filo va cambiando morfológicamente, en especial su ángulo, a medida que se reaviva con el fin de alargar su vida útil.

Aunque es difícil establecer los parámetros métricos de estas piezas debido a que la mitad están fragmentadas, un simple gráfico de distribución de puntos, reflejando su longitud y anchura, nos muestra que hay dos grupos: uno compuesto por piezas de $40-80 \mathrm{~mm}$ de longitud y 25-35 mm de anchura, y otro en el que la longitud supera los $100 \mathrm{~mm}$ y la anchura sobrepasa normalmente los $40 \mathrm{~mm}$ (Fig. 7; Tab. 1).

El estudio tecno-tipológico del utillaje de El Casetón de la Era no está aún finalizado, por lo que no podemos avalar o descartar por el momento la cadena operativa de producción de los dentales en el yacimiento.

\section{EL ANÁLISIS TRACEOLÓGICO. BASES PARA EL ESTUDIO}

Una primera preocupación del analista estriba en comprobar la posible conservación de residuos microscópicos orgánicos e inorgánicos adheridos a la superficie de las piezas, los cuales podrían desaparecer de no mediar una limpieza controlada. En condiciones normales se recomienda, por tanto, un lavado somero, con solo agua y jabón, para retirar el sedimento acumulado sobre el material. Esta acción no acarrea problemas para el posterior reconocimiento macro y microscópico de los rastros de uso.

Sin embargo, el que prácticamente todas las piezas de El Casetón de la Era muestren fuertes concreciones calcáreas, como mínimo en una de las caras, nos ha obligado a recurrir excepcionalmente a una estrategia de limpieza más agresiva. Consistió en sumergir los útiles en una solución muy baja (10\%-15\%) de ácido clorhídrico durante 4-5 minutos, e insistimos en que de manera excepcional porque se aplicó a los materiales en los que la concreción invadía la totalidad de los filos, nunca a aquellos en los que la costra era solo unifacial. De esta manera evitábamos deterioros en la superficie de las piezas y/o de las huellas.

Ya limpias las piezas, la observación ha conjugado el uso de una lupa binocular Olympus, y de un microscopio metalográfico Olympus BH2 cuyos aumentos van desde 50X a 400X. El análisis ha permitido apreciar el efecto pernicioso de algunas alteraciones de baja intensidad (lustre de suelo, efectos de alteración química), pero nada tan importante que impidiera observar el desarrollo excepcionalmente pronunciado de las huellas de uso de nuestras piezas ni descubrir a qué actividades se destinaron hace casi 5.000 años.

La hipótesis más barajada hasta ahora sobre estas piezas es que se trataba de elementos de hoz.

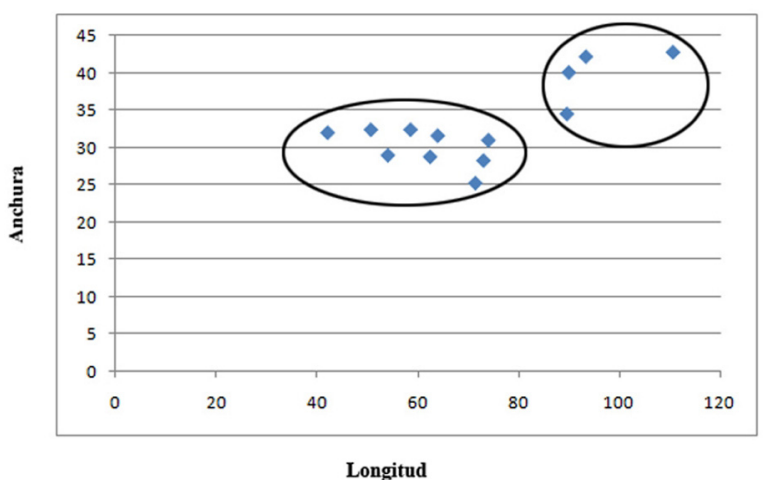

Fig. 7. El Casetón de la Era (Villalba de los Alcores, Valladolid). Longitud y anchura de los soportes bifaciales de sílex enteros analizados. 


\begin{tabular}{|c|c|c|c|c|c|c|c|c|c|}
\hline \multirow[b]{2}{*}{ N. ${ }^{\circ}$} & \multirow[b]{2}{*}{ Sigla } & \multirow[b]{2}{*}{$\begin{array}{l}\text { Contexto de } \\
\text { aparición }\end{array}$} & \multicolumn{3}{|c|}{ Tipometría } & \multirow[b]{2}{*}{$\begin{array}{l}\text { Peso } \\
\text { (g) }\end{array}$} & \multirow[b]{2}{*}{ Fracturas } & \multirow[b]{2}{*}{ Morfología } & \multirow[b]{2}{*}{ Uso } \\
\hline & & & $\begin{array}{c}\text { Longi- } \\
\text { tud } \\
(\mathbf{m m})\end{array}$ & $\begin{array}{l}\text { An- } \\
\text { chura } \\
(\mathrm{mm})\end{array}$ & $\begin{array}{c}\text { Espe- } \\
\text { sor } \\
(\mathrm{mm})\end{array}$ & & & & \\
\hline 1 & 2006/46/4000/1B/2 & $\begin{array}{c}\text { Nivel } \\
\text { superficial }\end{array}$ & 62,4 & 28,8 & 10,9 & 21 & No & $\begin{array}{c}\text { Cuadrilateral } \\
\text { Alargada }\end{array}$ & No \\
\hline 2 & $2006 / 46 / 4000 / 1 \mathrm{D} / 2$ & $\begin{array}{c}\text { Nivel } \\
\text { superficial }\end{array}$ & 63,2 & 36,8 & 13,6 & 35 & Proximal & $\begin{array}{c}\text { Triangular } \\
\text { Alargada }\end{array}$ & Sí \\
\hline 3 & $2006 / 46 / 4003 / 2 \mathrm{~A} / 24$ & Foso 1 & 29,1 & 22,8 & 9,2 & 7 & Distal & Fracturada & Sí \\
\hline 4 & $2006 / 46 / 4007 / 3 \mathrm{~B} / 9$ & Hoyo 7 & 27,1 & 35,6 & 10,9 & 13 & Proximal & Fracturada & No \\
\hline 5 & $2006 / 46 / 4020 / 3 \mathrm{~B} / 27$ & Foso 1 & 46,3 & 38,6 & 12,1 & 29 & Próximo-Distal & Fracturada & No \\
\hline 6 & 2006/46/4003/1A/2 & Foso 1 & 40,5 & 39,8 & 14,4 & 26 & Distal & $\begin{array}{c}\text { Cuadrilateral } \\
\text { Corta }\end{array}$ & Sí \\
\hline 7 & $2006 / 46 / 5059 / 3 \mathrm{C} / 60$ & Нoyo 45 & 89,6 & 34,5 & 11,7 & 43 & No & Trapezoidal & Sí \\
\hline 8 & $2006 / 46 / 5006 / 3 \mathrm{D} / 25$ & Foso 1 & 19,9 & 31 & 5,1 & 4 & $\begin{array}{c}\text { Latero-Próximo- } \\
\text { Distal } \\
\end{array}$ & Fracturada & Sí \\
\hline 9 & 2006/46/5006/3E/27 & Foso 1 & 38,5 & 33,9 & 11,3 & 14 & $\begin{array}{c}\text { Latero-Próximo- } \\
\text { Distal } \\
\end{array}$ & Fracturada & No \\
\hline 10 & $2006 / 46 / 5006 / 3 \mathrm{E} / 5 / 12$ & Foso 1 & 58,5 & 32,4 & 11,9 & 20 & No & $\begin{array}{l}\text { Triangular } \\
\text { Alargada }\end{array}$ & Sí \\
\hline 11 & $2006 / 46 / 5006 / 3 \mathrm{E} / 31$ & Foso 1 & 31,4 & 28,5 & 11,4 & 11 & Distal & Fracturada & Sí \\
\hline 12 & $2006 / 46 / 5006 / 3 \mathrm{E} / 3 / 32$ & Foso 1 & 50,6 & 32,4 & 13,4 & 26 & Proximal & $\begin{array}{c}\text { Cuadrilateral } \\
\text { Alargada }\end{array}$ & Sí \\
\hline 13 & $2006 / 46 / 5005 / 4 \mathrm{C} / 13$ & $\begin{array}{c}\text { Nivel de } \\
\text { ocupación }\end{array}$ & 93,4 & 42,1 & 13,3 & 49 & No & Trapezoidal & Sí \\
\hline 14 & $2006 / 46 / 6002 / 8 / 23$ & Foso 3 & 43,3 & 35,9 & 7,1 & 14 & Distal & Fracturada & Sí \\
\hline 15 & 2006/46/10046/17 & Hoyo 71 & 73 & 28,3 & 10,5 & 21 & No & $\begin{array}{c}\text { Triangular } \\
\text { Alargada }\end{array}$ & No \\
\hline 16 & $2006 / 46 / 10000 / 17$ & $\begin{array}{c}\text { Nivel } \\
\text { superficial }\end{array}$ & 110,7 & 42,7 & 14,9 & 62 & Lateral & $\begin{array}{c}\text { Cuadrilateral } \\
\text { Alargada }\end{array}$ & Sí \\
\hline 17 & 2006/46/SUP/02 & $\begin{array}{c}\text { Nivel } \\
\text { superficial }\end{array}$ & 63,9 & 31,6 & 10,8 & 23 & No & $\begin{array}{c}\text { Cuadrilateral } \\
\text { Alargada }\end{array}$ & Sí \\
\hline 18 & $2006 / 46 / 10010 / 25$ & Hoyo 58 & 31,1 & 34 & 12 & 13 & Distal & Fracturada & Sí \\
\hline 19 & 2006/46/5005/1B/01 & $\begin{array}{l}\text { Nivel de } \\
\text { ocupación }\end{array}$ & 71,4 & 25,3 & 9,9 & 20 & No & $\begin{array}{c}\text { Cuadrilateral } \\
\text { Alargada }\end{array}$ & Sí \\
\hline 20 & $2006 / 46 / 10000 / 15$ & $\begin{array}{c}\text { Nivel } \\
\text { superficial }\end{array}$ & 53,3 & 34,4 & 12,2 & 24 & Distal & $\begin{array}{c}\text { Cuadrilateral } \\
\text { Alargada }\end{array}$ & Sí \\
\hline 21 & 2006/46/SUP/03 & $\begin{array}{c}\text { Nivel } \\
\text { superficial }\end{array}$ & 48 & 37 & 12 & 26 & Proximal & $\begin{array}{c}\text { Triangular } \\
\text { Alargada }\end{array}$ & Sí \\
\hline 22 & 2006/46/SUP/01 & $\begin{array}{c}\text { Nivel } \\
\text { superficial }\end{array}$ & 72 & 31 & 10 & 26 & No & $\begin{array}{c}\text { Triangular } \\
\text { Alargada }\end{array}$ & Sí \\
\hline 23 & $2006 / 46 / 10054 / 23$ & Ноуо 73 & 44 & 35 & 11 & 19 & Proximal & Fracturada & No \\
\hline 24 & 2006/46/5087/1B/36 & Ноуо 55 & 42 & 30 & 9 & 11 & No & $\begin{array}{c}\text { Triangular } \\
\text { Corta }\end{array}$ & No \\
\hline 25 & 2006/46/10048/11 & Hoyo 70 & 25 & 55 & 29 & 21 & No & $\begin{array}{c}\text { Cuadrilateral } \\
\text { Alargada }\end{array}$ & Sí \\
\hline 26 & 2006/46/10058/38 & Hoyo 70 & 92 & 41 & 13 & 54 & No & $\begin{array}{c}\text { Cuadrilateral } \\
\text { Alargada }\end{array}$ & Sí \\
\hline
\end{tabular}

Tab. 1. Inventario de los dentales de sílex analizados de El Casetón de la Era (Villalba de los Alcores, Valladolid). Se detalla la procedencia, diversa información sobre su morfología y si están o no usados. 
Está llena de lógica si se valoran el frecuente lustre de los filos y el redondeamiento y las estrías observables incluso a nivel macroscópico. Sin embargo, el estudio traceológico ha deparado sorpresas inesperadas. El fuerte lustre de cereal que presentan buena parte de las piezas se asocia ordinariamente a otros desgastes muy específicos, propios de útiles empleados como dentales de trillo.

En 9, de las 26 piezas analizadas, se aprecia la superposición de huellas generadas por corte de cereales y por contacto con una materia tan abrasiva como la tierra, lo que solo puede ser resultado de un uso como trillos. Otras 9 presentan solo huellas producidas por roce intenso con la tierra, bajo la forma de fuertes abrasiones e innumerables estrías que recorren longitudinalmente el filo usado. En ambos casos se trata, sin duda, de los mismos rasgos que en su día sirvieron para que las láminas cananeas de sílex de ciertos yacimientos de la Edad del Bronce (IV milenio BC) de Irak, Siria y Turquía, dejaran de considerarse piezas de hoz y adoptaran la consideración de piedras de trillo, plenamente aceptada en la bibliografía (Anderson e Inizan 1994; Anderson et al. 2004, 2006; Gurova y Chavot 2007)(4).

En El Casetón, 6 piezas, en su mayoría incompletas y sin huellas de uso, deben ser dentales fracturados y desechados durante el proceso de elaboración, o bien piezas guardadas/almacenadas tras su manufactura. Por último, uno de los objetos no ha podido ser analizado por su mal estado de conservación y otro muestra huellas tan poco desarrolladas que solo nos atrevemos a decir, no sin dudas, que se utilizó sobre una materia vegetal indeterminada.

\section{LOS DENTALES O PIEDRAS DE TRILLO}

Uno de los rasgos relacionados con la trilla del cereal, apreciable a simple vista o palpando los filos, es el fuerte redondeamiento de estos y de las zonas elevadas de los vértices generados por el retoque. Tal grado de redondeamiento es directamente proporcional al tiempo de uso y al transcurrido desde el reavivado de los filos. La forma-

(4) Se ha hablado también de la presencia de láminas empleadas como piezas de trillo en contextos supuestamente calcolíticos de Bulgaria. Las dudas sobre su adscripción cronológica son consecuencia de la ausencia de dataciones absolutas y de los problemas de correlación de tales piezas con secuencias estratigráficas claras (Skakun 1992; Gurova 2001). tización inicial de los dentales pasa por elaborar un filo denticulado que tiende a rectilíneo. Posteriormente, el continuo trabajo y la abrasión que generan el corte de la paja y el roce con el suelo, redondean los filos y los embotan con facilidad. Para salvar dicho embotamiento y alargar la vida de las piezas, los filos son continuamente reavivados. En las estudiadas de El Casetón de la Era ha sido posible observar incluso distintos momentos de reavivado gracias a que la intensidad del pulido es heterogénea en según qué zonas o caras (Gurova y Chavot 2007). Así por ejemplo:

1. Hay piezas en las que la intensidad del pulido de uso, o incluso su ausencia en el interior de las melladuras del retoque, solo se aprecia en el área distal o proximal del filo denticulado. Donde se observa una menor intensidad de pulido, ha habido como mínimo un segundo momento de reavivado. Cuando en el interior de las melladuras no hay huellas, es evidente que fueron desechadas y se renunció a la reutilización. Aunque es difícil proponer una explicación general para el abandono de estas piezas, parece lógico pensar que algunas se rechazaron después de fracturarse durante el proceso de reavivado.

2. Si el reavivado afecta de manera desigual a ambas caras parece evidente que se efectuó en dos sesiones distintas, incidiendo primero en una cara y en otro momento en la opuesta.

Evidentemente, no podemos determinar el número de reavivados que se han realizado. Esa heterogénea intensidad de pulido en el exterior e interior de las melladuras o incluso su ausencia en estas últimas nos hablan únicamente de distintos momentos de reavivado.

Las piezas se caracterizan asimismo por la presencia de micropulido de cereal y/o de elementos abrasivos entre los que destacan las estrías, los redondeamientos y los microagujeros. Tales rastros tampoco se manifiestan siempre de manera similar en todas. Su grado de desarrollo e intensidad depende de la pieza e incluso de ciertas zonas de un mismo filo.

El rango de intensidad del micropulido es muy variable, desde piezas en las que está muy desarrollado y hay relativamente pocas estrías (Fig. 8: 18), hasta otras en las que los puntos de pulido apenas son visibles por la fuerte abrasión que han sufrido. Entre ambos polos hay una amplia gama de piezas en las que se documentan de manera conjunta, pero en distinto grado, pulidos, estrías, redondeamientos y microagujeros (Fig. 8: 6). 


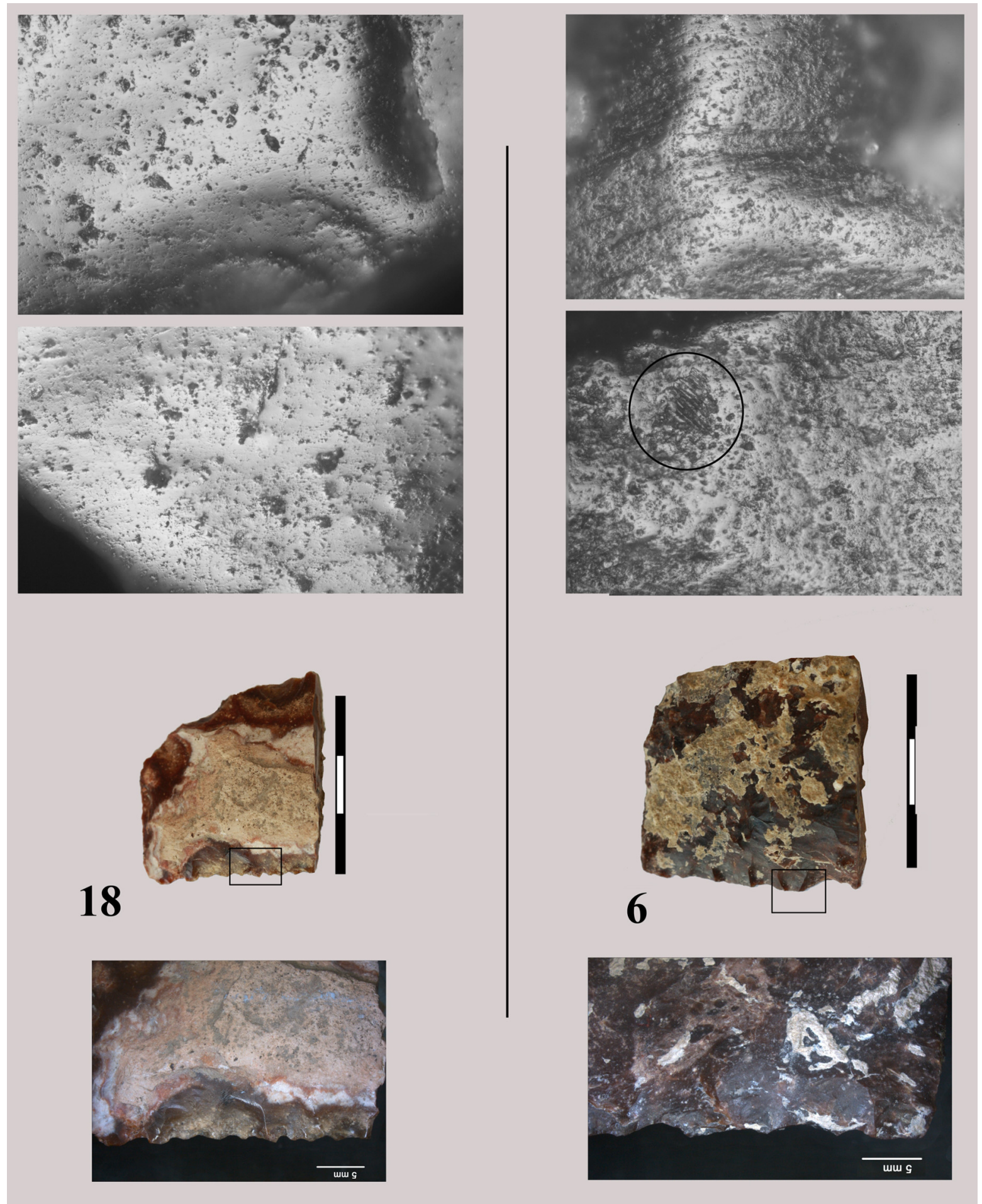

Fig. 8. El Casetón de la Era (Villalba de los Alcores, Valladolid): (6) Pieza con pulido de cereal asociado a numerosas estrías. En la segunda foto microscópica, en el interior del círculo, un fitolito de gramínea (cereal) identificado por P. C. Anderson. (18) Pieza con pulido de cereal muy desarrollado y escaso componente abrasivo. Fotos microscópicas a 100X tomadas en distintos puntos de las piezas 6 y 18 . Se especifican los números de inventario de los dentales de sílex en la tabla 1 . 
No es fácil pronunciarse sobre la razón de tal diversidad, pero a la hora de buscar respuestas resulta obligado tener en cuenta los siguientes factores:

1. La fase de la trilla en que la pieza intervino. La huella no es seguramente la misma en lascas usadas en el inicio del proceso, con el bálago enterizo formando una mullida parva sobre la era, que avanzado el mismo, con los tallos y las espigas ya cortados y las cuchillas virtualmente en contacto con el suelo. Parece lógico que, según el momento en el que la pieza se haya desprendido (accidental o deliberadamente) del tribulum, encontremos en ella más pulido de cereal o más elementos abrasivos (estrías, microagujeros e intensos redondeamientos).

2. Otro determinante de los pulidos es la tierra que pudiera llegar a la era con los haces de cereal. En este caso cabe que las huellas de pulido no fueran necesariamente de la fase más avanzada de la trilla.

3. Igualmente ha de tenerse en cuenta el efecto de los reavivados. Cuando se refresca el filo a una pieza con mucho lustre de cereal, desaparece buena parte del pulido generado por el uso previo. Si con posterioridad la pieza rehabilitada entra en contacto con el suelo, aparecerán abrasiones en la zona reavivada y se generarán estrías sobre los espacios que sobrevivan de la zona pulida inicialmente. El útil, en este caso, presentará estigmas de una trayectoria de uso.

4. Otra circunstancia a sopesar es el lugar que ocupa la pieza en el trillo. Es hipótesis aún por confirmar experimentalmente o mediante la observación de ejemplares modernos, pero parece lógico que el mayor peso y presión del trabajo recaiga sobre los pedernales insertados en medio de la tabla y no en las zonas marginales.

Una posibilidad que valoramos al principio es que el diferente grado de desarrollo del micropulido de cereal y del componente abrasivo fuera fruto de una reutilización. Es decir, que las piezas se hubieran empleado primero para segar y más tarde como elementos de trillo. Hemos desechado finalmente esta hipótesis porque la mayoría presentan en distinto grado abrasiones en forma de estrías, redondeamientos y microagujeros y porque no es efectivo el enmangamiento como hoces de piezas tan grandes y pesadas como las de $\mathrm{El} \mathrm{Ca-}$ setón de la Era (Figs. 9: 7 y 10: 16). Habría que atribuirlas, efectivamente, a hoces enormes, sin parangón a nivel etnográfico e histórico. La excepción podría ser la pieza pequeña 18 (Fig. 8) con huellas de cereal muy desarrolladas. Sin embargo, no descartamos que la longitud inicial fuera mayor y se tratara de un elemento reaprovechado.

El grado de abrasión es tan intenso que no podemos pensar en piezas usadas para cortar el cereal por la parte inferior de los tallos. Dicho procedimiento genera un micropulido de cereal claramente diagnóstico asociado simplemente a un mayor número de estrías y microagujeros, nada comparables con la fuerte abrasión y las innumerables estrías apreciables en las estudiadas.

P. Anderson y colaboradores (2004) también constataron esta variabilidad de huellas en las láminas cananeas y contemplaron la hipótesis de que pudiera guardar relación con el grado de humedad de las plantas trilladas y con las características de la superficie de la era. Son cuestiones que deberán examinarse en futuros trabajos experimentales. En cualquier caso, de hallarnos ante una reutilización, deberíamos encontrar el mismo grado de pulido de cereal e idéntica cantidad de estrías en toda la pieza, lo que no sucede entre distintas zonas del filo e incluso entre ambas caras.

Menos dudas suscitan las piezas que apenas presentan pulido y cuyos rasgos más característicos son las fuertes abrasiones en forma de numerosas estrías, intensos redondeamientos e innumerables microagujeros. Se trata de piezas de trillo con rastros idénticos a los documentados en dentales de sílex modernos (Fig. 10).

Sobre tales piezas se atestiguan sistemáticamente estrías longitudinales paralelas al filo efecto de un movimiento de corte, pero también, puntualmente, estrías profundas de dirección transversal. Según nuestro parecer, resultan de la presión que ejerce el trillo en el momento de situarlo en la era (Fig. 9: 7). Por último, las estrías localizadas en uno de los laterales de las melladuras del filo retocado/ reavivado, denotan que el movimiento fue unidireccional, lo que sería de esperar en un trillo.

El desarrollo de la huella es tan acusado que en muchas piezas no cuesta trabajo determinar hasta dónde llegaba el límite de la zona de enmangamiento. Gracias a dicho detalle puede afirmarse que aproximadamente un tercio del ancho de las piezas, en ciertos casos hasta la mitad, estaba insertado o embutido en su bastidor.

La inserción de las lascas recibe el nombre de empedrado o enchinado. Puede hacerse de dos maneras. La más común y la que pervivió en la Península Ibérica hasta los trillos más recientes consiste en fijar a presión los dentales en los cortes hechos 


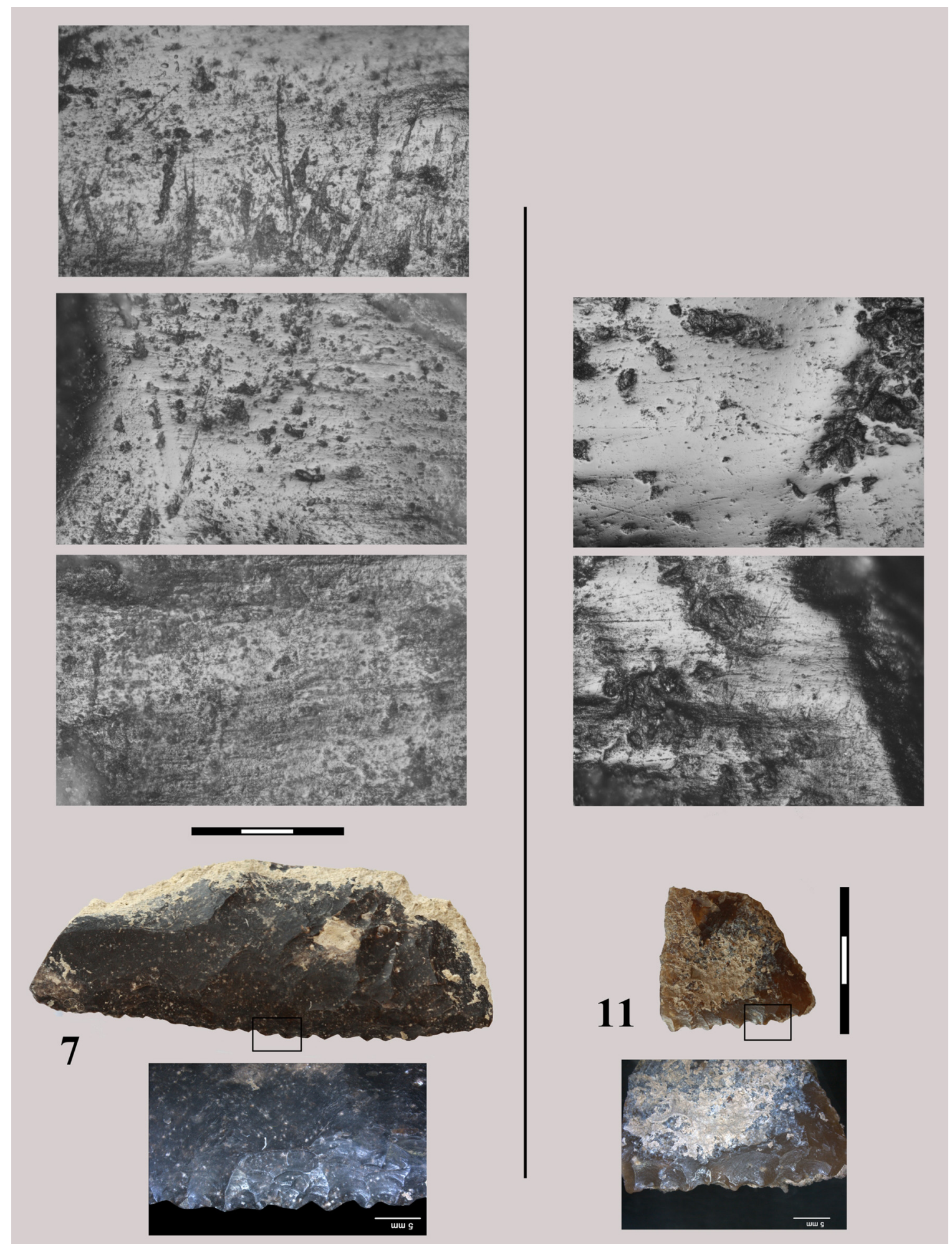

Fig. 9. El Casetón de la Era (Villalba de los Alcores, Valladolid). Piezas en las que se observan áreas con mucho pulido de cereales y otras donde el pulido ha sido substituido por fuertes abrasiones y numerosas estrías. Fotos microscópicas a 100X. Se especifican los números de inventario de los dentales de sílex en la tabla 1. 


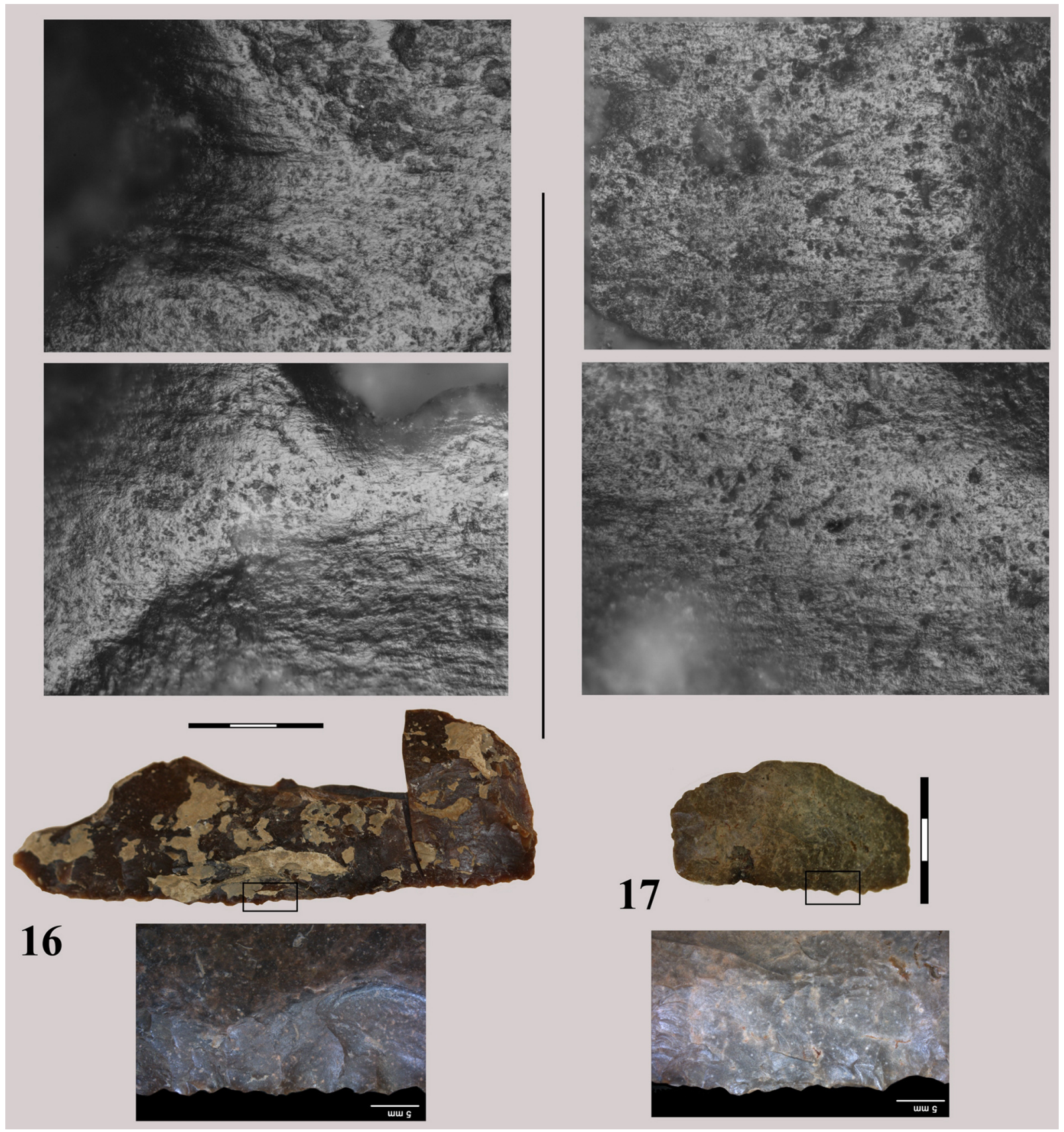

Fig. 10. El Casetón de la Era (Villalba de los Alcores, Valladolid). Piezas con estrías, intenso redondeamiento y microagujeros resultado del contacto con el suelo durante su uso como piezas de trillo. Fotos microscópicas a 100X. Se especifican los números de inventario de los dentales de sílex en la tabla 1.

previamente en una tabla mediante golpes de escoplo. Pero P. Anderson y colaboradores (Anderson et al. 2004; Anderson et al. 2006) sospechan que el trillo armado con las amplias láminas de sílex cananeas debió tener una estructura diferente. Vendría a ser una especie de balsa formada por troncos unidos con cuerdas en cuyas juntas se disponía una sustancia pegajosa o mastique en la que, debidamente alineadas, quedaban sujetas las cuchillas de piedra (Fig. 11).

Trab. Prehist., 69, N. ${ }^{\circ}$ 1, enero-junio 2012, pp. 133-148, ISSN: 0082-5638

doi: $10.3989 /$ tp.2012.12084 

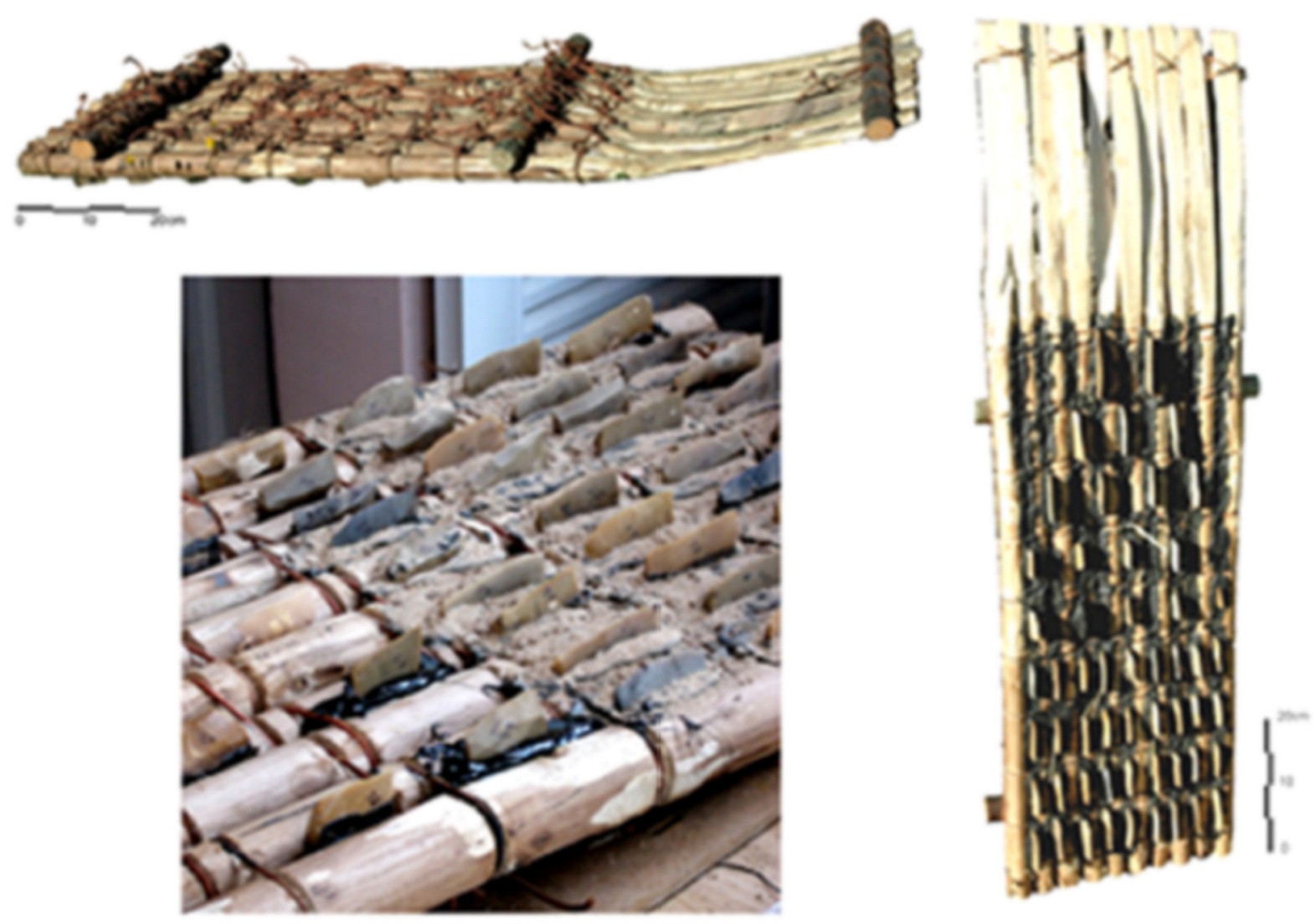

Fig. 11. Reconstrucción del modelo de trillo planteado por P. C. Anderson para la inserción y uso de las láminas cananeas (imágenes cedidas por P. C. Anderson).

De los 19 dentales -acreditados como tales con seguridad- de El Casetón de la Era 11 (58\%) no nos han llegado enteros. Ello induce a pensar que se abandonaron al fragmentarse durante su utilización o durante los procesos de reparación y reavivado. Esto explicaría por qué algunas de estas piezas, después de ser reavivadas, no han vuelto a ser usadas o se usaron durante muy poco tiempo.

El variable tamaño de los soportes completos sugiere el empleo en un mismo trillo de piezas de distintas dimensiones y, sin embargo, no siempre igual de bien clavadas en el mastique, cosa que poco puede extrañar cuando los reavivados parecen haber estado a la orden del día. Nada nos permite imaginar, por último, el tamaño de los trillos ni el número aproximado de dentales requerido para componer uno. Pero está claro que haberlos los hubo.
Finalmente, procede apuntar la existencia de fitolitos en la pieza 6 (Fig. 8), que P. Anderson identifica con la epidermis de un tallo de gramíneas de cereal. Es evidente la necesidad de que en el futuro se acometan estudios de este tipo a fin de esclarecer, a través de los fitolitos conservados en el filo de los pedernales, la naturaleza de las plantas trilladas.

\section{PIEZAS NO USADAS}

En el conjunto de El Casetón de la Era, tenemos 6 piezas sin huellas de uso (Fig. 12) que presentan caracteres morfológicos comunes a las utilizadas. Consideramos dentales de trillo los que están perfectamente acabados y dispuestos para su empleo inmediato (Fig. 12: 1). Serían piezas excedentarias almacenadas para un uso posterior. 


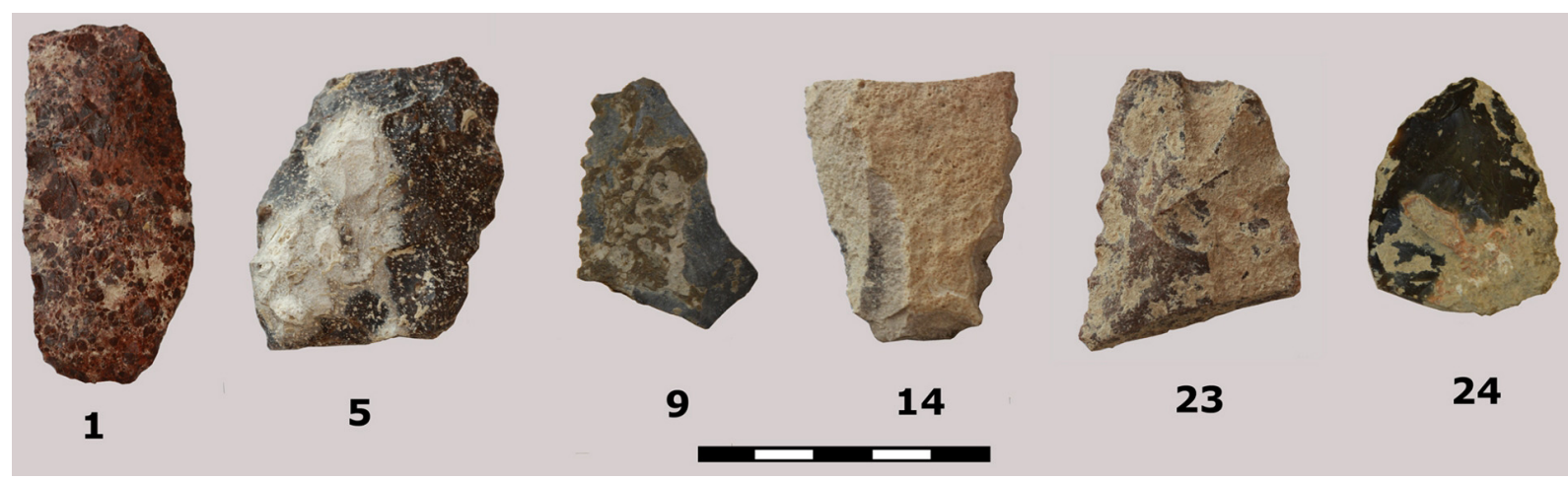

Fig. 12. Dentales de sílex sin usar de El Casetón de la Era (Villalba de los Alcores, Valladolid). La 14 se catalogó como no analizable. Se especifican los números de inventario (Tab. 1).

En otros casos da la sensación que las piezas se han fracturado durante el proceso de elaboración, por cuanto alguna parte aún no está configurada. En ocasiones, aunque el filo denticulado ya esté preparado, la parte que acabará embutida en el vientre del trillo no está del todo confeccionada o ni siquiera retocada (Fig. 12: 9 y 24).

Incluso, hay piezas más reveladoras (Fig. 12), con una de las caras sin retocar o solo parcialmente retocada, como las piezas 5, 23 y seguramente la 14 catalogada como no analizable.

En definitiva, nos encontramos con un amplio abanico de variables, desde piezas preparadas que se almacenaron para substituir a las que se habían roto, desprendido o gastado, hasta otras que perecieron por fractura durante el proceso de elaboración. Entre estas últimas algunas se rompieron al principio de la configuración, al iniciar el filo denticulado, y otras a punto de finalizarse.

\section{CONCLUSIONES}

El utillaje estudiado de El Casetón de la Era permite reconocer por primera vez en la Península Ibérica que durante la Edad del Cobre, hacia el 2800 a.C., las comunidades humanas conocían y usaban el trillo para el procesado de cereales (5). No sabemos exactamente su forma ni su tamaño, pero para el empedrado de su vientre empleaban piezas de sílex de unas características

(5) Una pieza de trillo documentada en el yacimiento Forcalquier-La Fare (Francia) se ha atribuido a la fase más antigua de la ocupación hacia el 3000-2500 a.C. (Khedhaier et al. 2003). morfológicas y morfométricas muy concretas. Tales piezas difieren enormemente de las de los trillos actuales, pero se asemejan a las utilizadas en el Próximo Oriente durante el Calcolítico y el Bronce Antiguo.

Sospechamos que este tipo de piezas están también presentes en muchos yacimientos de la Edad del Cobre de la Península Ibérica, pero han sido confundidas con elementos de hoz, por lo que sería interesante abordar un estudio de conjunto, mucho más ambicioso, con otras comparables de diferentes áreas. De esta manera intentaríamos conocer el papel de este tipo de artilugios en relación a las actividades económicas realizadas por los grupos estudiados y saber cuándo se inició el uso de los trillos con dentales de sílex. Quizás previamente se emplearan para trillar sistemas como el pisoteo de animales que son difíciles de discernir en el registro arqueológico. En un futuro será necesario establecer estrategias arqueológicas dirigidas a reconocer las posibles zonas correspondientes a las eras y colaborar con investigadores especializados en el estudio de las semillas y los fitolitos para intentar resolver esta cuestión.

El empleo de trillos indica que estas sociedades requerían de un instrumento complejo y efectivo para procesar la cantidad de cereal que producían. Sin duda, los trillos solo se usan cuando la producción es importante, pues de lo contrario se emplean otros sistemas para la separación de la espiga del tallo o el desprendimiento de las semillas, caso del golpeo con mayales o del golpeo de los tallos sobre una superficie dura (un tronco o una pared). 
Sin duda, con este trabajo se abren nuevas perspectivas de estudio sobre la producción del cereal en la Prehistoria Reciente y su papel en la economía de las comunidades humanas de entonces. Pero, sea como fuere, aún sigue quedando mucho por hacer.

\section{AGRADECIMIENTOS}

A la Dra. Patricia C. Anderson por la lectura crítica de este trabajo, por su asesoramiento y la cesión de las imágenes relacionadas con la reconstrucción de los trillos (Fig. 11).

\section{BIBLIOGRAFÍA}

Anderson, P. C.; Chabot, J. y Van Gijn, A. 2004: "The functional riddle of 'Glossy' Canaanean blades and the Near Eastern threshing sledge". Journal of Mediterranean Archaeology 17: 87-130.

Anderson, P. C. e Inizan, M. L. 1994: "Utilisation du tribulum au début du IIIe millénaire: des lames cananéennes lustrées à Kutan (Ninive V) dans le región de Mossoul, Iraq". Paléorient 20: 85-103.

Anderson, P. C.; Georges, J. M.; Vargiolu, R. y Zahouani, H. 2006: "Insights from a tribological analysis of the tribulum". Journal of Archaeological Science 33: 1559-1568.

Benavente, J. A. 1992: "Las industrias de foliácieos del Bajo Aragón. Su relación con el litoral mediterráneo". En M. P. Utrilla (ed.): Aragón/Litoral Mediterráneo: intercambios culturales durante la Prehistoria. Homenaje a Juan Maluquer de Motes (Zaragoza 1990): 569-586. Zaragoza.

Blasco, C.; Delibes, G.; Baena, J.; Liesau, C. y Ríos, P. 2007: "El poblado calcolítico de Camino de las Yeseras (San Fernando de Henares, Madrid): un escenario favorable para el estudio de la incidencia campaniforme en el interior peninsular". Trabajos de Prehistoria, 64 (1): 151-163.

Bronk Ramsey, C. 2005: "Improving the resolution of radiocarbon dating by statistical analysis". En T. E. Levy y T. F. G. Higham (eds.): The Bible and Radiocarbon Dating: Archaeology, Text and Science. Equinox. London: 57-64.

Carrión, E.; Baena, J.; Iniesta, J. y Blasco, C. 2004: "Aproximación a las diferencias técnicas, tipológicas y de explotación de la industria lítica entre los horizontes Protocogotas y Cogotas I, a través de los datos del Caserío de Perales del Río (Getafe, Madrid)". En L. Hernández y M. Hernández (eds.): La Edad del Bronce en tierras valencianas y zonas limitrofes. Ayuntamiento de Villena. Villena: 603-612.
Carvalho, A. F. 2008: A neolitização do Portugal Meridional. Os exemplos do Maciço Calcário Estremenho e do Algarve Ocidental. Promontoria Monografica 12. Universidade do Algarve. Braga.

Clop, X.; Gibaja, J. F.; Palomo, A. y Terradas, X. 2001: "Un utillaje lítico especializado: las 'grandes láminas' de sílex del Noreste de la Península Ibérica". XXVII Congreso Nacional de Arqueología (Huesca 2003). Bolskan 18: 311-322.

Clop, X.; Gibaja, J. F.; Palomo, A. y Terradas, X. 2006: "Approvisionnement, production et utilisation des grandes lames en silex dans le nord-est de la Péninsule Ibérique". En J. Vaquer y F. Briois (dir.): $L a$ fin de l'Âge de Pierre en Europe du Sud. Archives d'Écologie Préhistorique. Toulouse: 233-246.

Delibes, G.; Crespo, M.; Fernández-Manzano, J.; Herrán, J. I. y Rodríguez-Marcos, J. A. 2009a: “¿Stonehenge en Tierra de Campos? Excavaciones en el yacimiento de la Edad del Cobre de El Casetón de la Era (Villalba de los Alcores, Valladolid)". En E. Wattenberg (ed.): Conocer Valladolid. II Curso de Patrimonio Cultural (2008-2009). Real Academia de Bellas Artes de la Purísima Concepción. Valladolid: 15-33.

Delibes, G.; Crespo, M.; Fernández-Manzano, J.; Herrán, J. I. y Rodríguez-Marcos, J. A. 2009b: “Un recinto de fosos calcolítico en el valle medio del Duero: El Casetón de la Era (Villalba de los Alcores, Valladolid)". En Actas de las IV Jornadas Científicas de Patrimonio Arqueológico en la Comunidad de Madrid (Madrid 2007): 241-250. Madrid.

Delibes, G. y Herrán, J. I. 2007: La Prehistoria, Colección Biblioteca Básica de Valladolid, Diputación Provincial de Valladolid. Valladolid.

Delibes, G.; Herrán, J. I.; Santiago, J. y Val, J. del. 1995: "Evidence for social complexity in the Copper Age of the Northern Meseta". En K. Lillios (ed.): The origins of Complex Societies in Late Prehistoric Iberia. International Monographs in Prehistory. Archaeological Series 8, Ann Arbor Michigan: 44-63.

Díaz del Río, P. 2003: "Recintos de fosos del III milenio a.C. en la Meseta peninsular". Trabajos de Prehistoria, 60 (2): 61-78.

Gibaja, J. F. 2003: Comunidades Neolíticas del Noreste de la Península Ibérica. Una aproximación socio-económica a partir del estudio de la función de los útiles líticos, British Archaeological Reports, International Series S1140. Archaeopress. Oxford.

Gibaja, J. F.; Palomo, A. y Terradas, X. 2005: "Producción y uso del utillaje lítico durante el mesolítico y neolítico en el Noreste de la Península Ibérica". III Congreso del Neolítico en la Península Ibérica (Santander 2003): 223-231. Santander.

Gibaja, J. F.; Palomo, A.; Terradas, X. y Clop, X. 2004: "Útiles de siega en contextos funerarios del 3500-1500 cal ANE en el Noreste de la Península 
ibérica: El caso de las grandes láminas de sílex". Cypsela, 15: 187-195.

Gurova, M. 2001: "Eléments de tribulum de BulgarieRéférences ethnographiques et contexte préhistorique”. Archaeologia Bulgarica 5: 1-19.

Gurova, M. y Chabot, J. 2007: "Typologie, fonction, traces d'usure et contexte: où est le juste milieu? Exemples de Bulgarie, de Troie et de Mésopotamie septentrionale". En A. Bain, J. Chabot y M. Moussette (eds.): La mesure du passé: contributions à la recherche en archéométrie (2000-2006). British Archaeological Reports, International Series 1700. Archaeopress. Oxford: 75-87.

Khedhaier, R.; Verdin, P.; Furestier, R.; Lemercier, O. y Müller, A. 2003: "Dépiquage au tribulum au Néolithique final dans le Sud-Est de la France. Indices convergents de la tracéologie et de l'analyse des phytolithes. Le cas du site de Forcalquier-La Fare (Alpes-de-Haute-Provence)". En P. C. Anderson, L. S. Cummings, T. K. Schippers y B. Simonel (eds.): Le traitement des récoltes: un regard sur la diversité du Néolithique au present. Actes de XXIII Rencontres Internationales d'Archéologie et d'Histoire d'Antibes, 2002: 477492. Antibes.

Márquez, J. E. 2001: “De los 'campos de silos' a los 'agujeros negros': Sobre pozos, depósitos y zanjas en la Prehistoria Reciente del Sur de la Península Ibérica". SPAL 10: 207-220.
Márquez, J. E. 2006: "Sobre los depósitos estructurados de animales en yacimientos con fosos del sur de la Península Ibérica". En E. Weiss-Krejci (ed.): Animais na Pré-historia e Arqueologia da Peninsula Ibérica. Actas del IV Congresso de Arqueología Penínsular (Faro 2004): 15-25. Braga.

Márquez, J. E. y Jiménez, V. 2008: "Claves para el estudio de los Recintos de Fosos del Sur de la Península Ibérica”. ERA-Arqueología 8: 158-171.

Reimer, P. J.; Baillie, M. G. L.; Bard, E.; Bayliss, A.; Beck, J. W.; Blackwell, P. G.; Buck, C. E.; Burr, G. S.; Cutler, K. B.; Damon, P. E.; Edwards, R. L.; Fairbanks, R. G.; Friedrich, M.; Guilderson, T. P.; Herring, C.; Hughen, K. A.; Kromer, B.; McCormac, F. G.; Manning, S. W.; Ramsey, C. B.; Reimer, P. J.; Reimer, R. W.; Remmele, S.; Southon, J. R.; Stuiver, M.; Talamo, S.; Taylor, F. W.; Van der Plicht, J. y Weyhenmeyer, C. E. 2004: "IntCal04 Terrestrial radiocarbon age calibration, 0-26 cal kyr BP”. Radiocarbon 46, 3: 1029-1058.

Siret, L. 1913: Questions de Chronologie et d'Ethnographie Ibériques. I. De la fin du Quaternaire a la fin $d u$ Bronze. Paul Geuthner. Paris.

Skakun, N. 1992: "Evolution des techniques agricoles in Bulgarie chalcolithique (d'après les analyses tracéologiques)". En P. Anderson (ed.): Préhistoire de l'agriculture: nouvelles approches expérimentales et ethnographiques. Monographie du Centre de Recherche en Archéologie 6, CNRS. París: 289-303. 